\title{
INTERNATIONAL Innovative recruitment and clinical orientation programme to manage NHS junior doctor shortfall: A district hospital experience
}

\author{
Authors: Syed Rehan Quadery, ${ }^{\mathrm{A}}$ Hamid Roodbari, ${ }^{\mathrm{B}}$ Pradeep Pardeshi, ${ }^{\mathrm{C}}$ Dilip Shah, ${ }^{\mathrm{D}}$ Hira Ahmed, ${ }^{\mathrm{E}}$ Seema Jain, ${ }^{\mathrm{F}}$ \\ Jason Saridis, ${ }^{G}$ Shakil Rahman, ${ }^{\text {A }}$ Nithiyananthan Ratnasingam, ${ }^{E}$ Caroline Ebdon, ${ }^{\text {H }}$ Richard Bogle, ${ }^{\mathrm{I}}$ James Marsh, \\ Ruth Charlton, ${ }^{\mathrm{J}}$ Guan Lim, ${ }^{\mathrm{K}}$ David Makanjoula, ${ }^{\mathrm{L}}$ Daniel Camp ${ }^{\mathrm{M}}$ and Simon Winn ${ }^{\mathrm{K}}$
}

\section{Background}

International medical graduates (IMGs) contribute significantly towards the NHS care provision. No standardised clinical orientation programme (COP) for IMGs new to the NHS exists.

\section{Objective}

Our objective was to describe recruitment and retention strategies for junior doctors (JDs) in general medicine and develop a framework to anticipate outcomes of these interventions using the realist evaluation methodology.

\section{Methods}

We performed quality improvement interventions of recruitment and COP for new entrant IMGs in our organisation employed between December 2017 and April 2019.

\section{Results}

Twenty-three IMGs were recruited, $96 \%$ successfully completed the COP with a mean contract duration of $13 \pm 5$ months. From the academic year $2017 / 18$ to $2018 / 19$, mean JD post

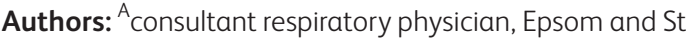
Helier University Hospitals NHS Trust, Carshalton, UK; ${ }^{B}$ doctoral Researcher, University of Sheffield, Sheffield, UK; ${ }^{C}$ consultant physician, Epsom and St Helier University Hospitals NHS Trust, Carshalton, UK; ${ }^{\mathrm{D}}$ consultant acute physician, Epsom and St Helier University Hospitals NHS Trust, Carshalton, UK; ${ }^{E}$ clinical lead, Epsom and St Helier University Hospitals NHS Trust, Carshalton, UK; ${ }^{\text {F }}$ consultant renal physician, Epsom and St Helier University Hospitals NHS Trust, Carshalton, UK; ${ }^{G}$ medical staffing manager Epsom and St Helier University Hospitals NHS Trust, Carshalton, UK; ${ }^{\mathrm{H}}$ clinical tutor for locally employed doctors, Epsom and St Helier University Hospitals NHS Trust, Carshalton, UK; I director medical Education, Epsom and St Helier University Hospitals NHS Trust, Carshalton, UK; ] joint medical director, Epsom and St Helier University Hospitals NHS Trust, Carshalton, UK; ${ }^{\text {Koint }}$ clinical director, Epsom and St Helier University Hospitals NHS Trust, Carshalton, UK; ' 'core medical training programme director, Epsom and St Helier University Hospitals NHS Trust, Carshalton, UK; ${ }^{\mathrm{M}}$ general manager, Epsom and St Helier University Hospitals NHS Trust, Carshalton, UK occupancy increased from $54 \pm 3$ to $73 \pm 4$ JDs $(p<0.001)$ and JD locum spend fell by $£ 1.9$ million.

\section{Conclusion}

Our structured COP provides a stable, trained and financially sustainable JD workforce. Application in broader NHS settings is recommended.

KEYWORDS: Health service research, quality improvement, medical education, realist theory, clinical orientation programme

DOI: $10.7861 /$ fhj.2019-0047

\section{Introduction}

There is an increasing pressure on the NHS to continue to provide optimal healthcare to the increasingly ageing population with complex medical problems. ${ }^{1}$ This manifests in a setting of reduced funding for community social services and national healthcare. ${ }^{2,3}$ Additionally, the UK medical workforce is undergoing demographic change with increased job sharing and part-time working models. ${ }^{4,5}$ Furthermore, between 2014 and 2016, the UK saw a $9 \%$ reduction in EU doctors relocating to the UK following General Medical Council (GMC) rulings requiring European medical graduates to evidence English language proficiency and the UK's departure from the EU ('Brexit') on 31 January 2020 is likely to further contribute to reduced migration of European doctors to the UK. ${ }^{6,7}$ Moreover, implementation of a new junior doctors (JDs) contract in 2016 was associated with some UK-based JDs forfeiting UK training posts, particularly in the acute medical specialties, electing to take work abroad. ${ }^{8-10}$ This scenario has helped drive a lucrative locum agency industry. ${ }^{11}$ Finally, application of the European Working Time Directive to the healthcare sector has curtailed JDs working hours which, in turn, has set in motion widespread shift-based working patterns, increased workload intensity and recognised risk of professional burnout, encouraging JDs to seek work abroad or to reduce their working hours. ${ }^{6,12,13}$ To address workforce shortages, the British government has proposed to open five new medical schools to expand undergraduate intake by $25 \% .^{10}$ The steep rise in medical workforce is unlikely to be felt before $2025 .^{14}$ 
International medical graduates (IMGs) are the second largest group of doctors employed by the NHS, constituting $30-40 \%$ of the JD workforce. ${ }^{15}$ Nevertheless, there remain over 6,000 doctor vacancies. ${ }^{16}$ In part, this shortfall is managed by employing temporary staff at premium rates, imposing significant cost pressures. ${ }^{11}$ Worryingly, the Office for National Statistics has shown a near $100 \%$ rise in locum doctor use by NHS hospitals in England between 2009 and 2015..$^{17}$ According to NHS Improvement, in 2015 there were over 16,000 locum doctors working in NHS hospitals in England, costing $£ 1.3$ billion between 2015-2016. ${ }^{17}$ The NHS needs a stable and trained workforce which is financially sustainable. In 2018 there was a 50\% increase in the number of IMGs coming to the UK and taking UK medical licensing examinations. ${ }^{6}$ Tapping into this resource by recruitment of additional doctors into the NHS is a potential short- to mediumterm solution to the medical workforce problem and aligns with the Interim NHS people plan. ${ }^{18}$

However, IMGs seeking employment in the NHS face multiple challenges: adapting to a new culture, language barriers, unfamiliar training systems, medico-legal framework, work duties and skills. ${ }^{19-21}$ These challenges can affect performance, career development and wellbeing as well as patient safety. A robust orientation programme would anticipate and mitigate such challenges and facilitate smooth transition into productive working in the NHS. ${ }^{22}$ Many IMGs joining the NHS find themselves unprepared as they are exposed to independent unsupervised work, sometimes with only minimal prior experience and training and without any formal assessment of their competence and knowledge of the local systems. There is no standardised orientation programme available for IMGs working in departments of general internal medicine (GIM) in the NHS.

Our trust has developed quality improvement interventions to expand a stable and trained medical workforce by improving the processes of recruitment, support, orientation, training, assessment, and integration of IMGs into the workforce.

This paper describes recruitment and retention interventions for locally employed JDs into our division of GIM with a particular focus on designing a novel, structured and standardised clinical orientation programme (COP) for IMGs new to the NHS. Realist evaluation methodology was used to develop a framework in the form of a context-mechanism-outcome (CMO) configurations to provide anticipated outcomes of these interventions.

\section{Methods}

\section{Setting}

Epsom and St Helier University Hospitals NHS Trust consists of two district general hospitals with a combined medical bed base of 425 . The GIM division employs 48 senior house officer ( $\mathrm{SHO}$ ) and 25 registrar-grade doctors, most of whom are on on-call rotas. Nearly half are UK-based trainee doctors, nationally recruited through open competition. The remaining JD posts are recruited locally by the trust. However, a majority of the locally employed doctor posts have remained unfilled, resulting in increased cost and reliance on high-cost locum doctors.

\section{Intervention 1: recruitment}

We recruited two grades of IMGs; SHO- and registrar-equivalent, based on prior clinical experience. These doctors were recruited via two routes.
> Route $\mathrm{A}$ : Less experienced doctors with GMC registration and had passed UK medical licensing examinations. These doctors were mainly SHO-equivalent, receiving their certificate of sponsorship (Tier 2) from our trust. A proportion of these doctors had successfully completed the trust's honorary clinical attachment programme. Recruitment (from successful interview to starting work) took up to 2 months.

> Route B: Doctors with extensive home country postgraduate medical experience at SHO- or registrar-equivalent level. GMC registration was gained via the Royal College of Physicians (RCP) sponsored Medical Training Initiative (MTI) scheme. The certificate of sponsorship (Tier 5) was offered via the Academy of Medical Royal Colleges. Recruitment (from successful interview to starting work) took up to 6 months.

Prospective candidates were sourced via social media and personal contacts. A telephone screening interview was conducted by a consultant physician and successful candidates advised to apply online to nationally advertised vacancies. Shortlisting was carried out by two consultant physicians. Thirty-minute interviews were predominantly face-to-face (others via video Skype) and conducted by two consultant physicians with human resources $(\mathrm{HR})$ representation. The interview format consisted of three sections: curriculum vitae review, clinical case scenarios and ethical scenarios. Upon successful interview, doctors were contacted by a consultant physician and informed of the outcome within a few hours. The HR department followed up with a conditional job offer via email within a few days.

\section{Intervention 2: clinical orientation programme}

Newly recruited IMGs underwent a structured COP (SHOs for 6 weeks; registrars for 12 weeks). The COP pathways are presented in Fig 1. Throughout orientation, IMGs were supernumerary, receiving close clinical supervision, mentoring and pastoral support, and completed multiple assessments. At the end of the COP and upon successful completion of specified targets, individual doctors were confirmed competent to work in more independent roles as seniority-relevant JDs by their respective educational supervisor. Essential criteria for SHOs and registrars to progress beyond the COP are shown in Fig 1.

The training was provided under an umbrella called 'The Academy', under the leadership of the training programme director. There was a core committee consisting of members from the medicine division, HR, postgraduate medical education, consultant physicians and the trust's responsible officer. Other stakeholders included the clinical and educational supervisors for these doctors.

\section{Data collection and analysis}

Multi-department progress updates and meetings inviting key stakeholders including clinicians and senior managers from the departments of medicine, $\mathrm{HR}$, postgraduate medical education and trust executive representation were initiated early on in the project. During these meetings, concerns with junior doctor shortfall and the consequent impact on patient care, staff wellbeing and financial constraints imposed by this shortage were outlined. This provided a framework to identify contextual factors and develop mechanisms of interventions to improve recruitment and retention of JDs.

Descriptive data are presented using mean \pm standard deviation. Comparisons between the two groups pre- and 


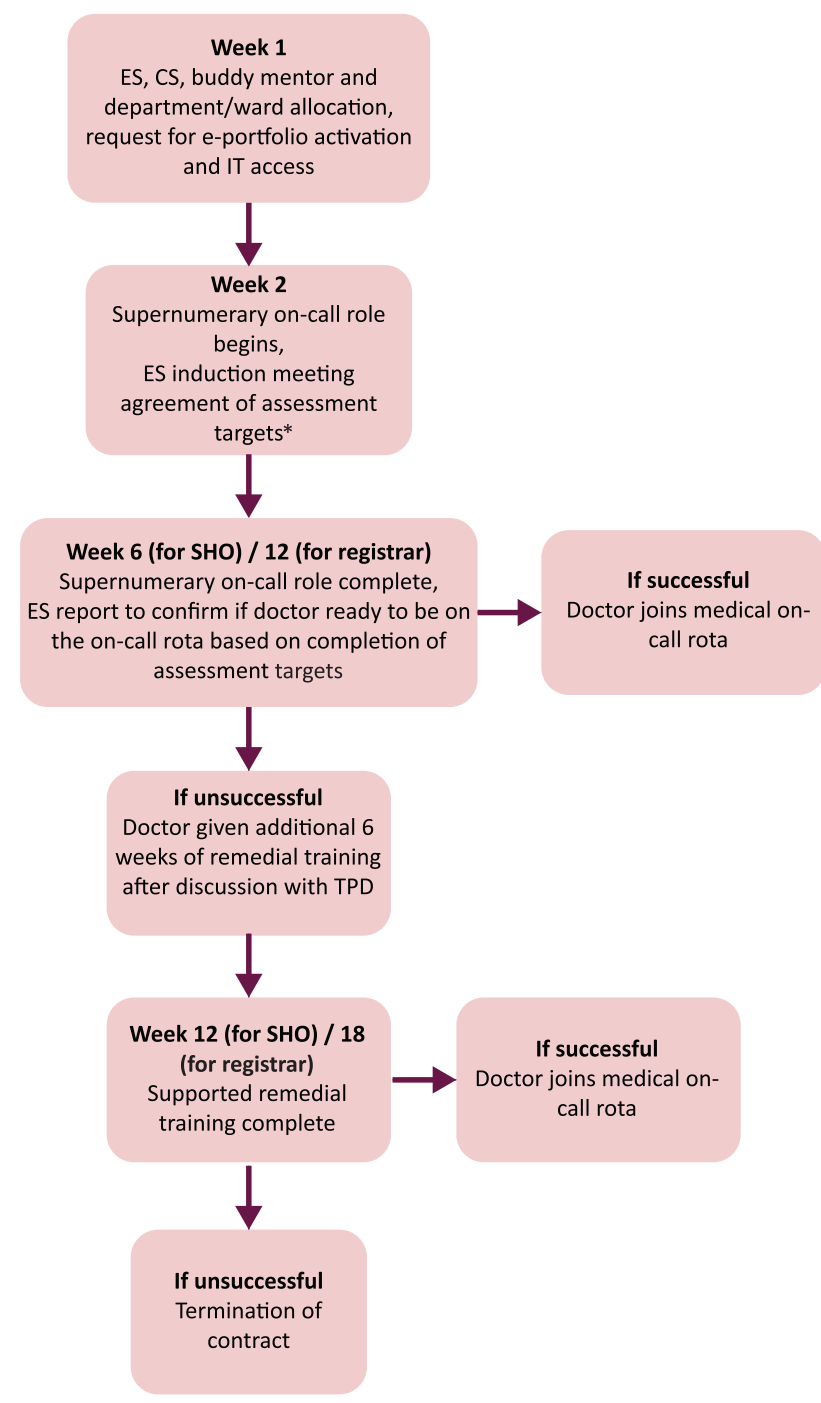

Fig 1. Clinical orientation programme pathway and assessment for senior house officer (foundation year-2 doctor: 6 weeks' duration) and registrar (specialty training year-3 doctor: 12 weeks' duration) grade doctors. "Assessment targets for senior house officers and registrars include competency in using trust IT systems; familiarity and understanding of local policies, guidelines and safe prescribing as well as ward round documentation standards; clerking and presenting patients to consultants on the acute medical unselected take; review of management of top acute medical conditions; knowledge and communication of personalised treatment escalation planning, do not attempt resuscitation policy and end-of-life care pathways; management of frail elderly patients with multiple comorbidities (including dementia and delirium assessment); performance of core bedside procedures (those expected at the end of the UK Foundation Programme); and mandatory trust induction and modules, consultant feedback report, registrar feedback report, completion of the orientation on-call as per rota, satisfactory attendance in departmental teaching, satisfactory interim educational supervisors report and advance life support provider (for registrars only). $\mathrm{CS}=$ clinical supervisor; $\mathrm{ES}=$ educational supervisor; $\mathrm{SHO}=$ senior house officer; TPD = training programme director.

post-intervention were made using the t-test for continuous data. The impacts of the interventions are assessed using the realist evaluation approach. Contexts (ie what are the conditions in which the intervention is effective?), mechanisms (ie what makes the intervention work?) and outcomes (ie which improvements in the organisation can be observed?) were collated into CMO configurations (where contexts + mechanisms = outcomes). ${ }^{23,24}$ Criteria for doctors joining our COP are described.

> Inclusion: Any medical graduate from outside the UK or EEA countries applying for their first medical job in the NHS. Such candidates were recruited to the trust and joined the COP between 01 December 2017 and 01 April 2019 and followed up till they left the trust or the census date of 09 September 2019.

> Exclusion: IMGs who had previously worked in the NHS or who resigned from the job before completion of the COP or within their first 3 months of joining the trust.

\section{Results}

The realist evaluation $\mathrm{CMO}$ configurations detailing the methodology of the behavioural changes implicit to the quality improvement work are shown in Table 1. Seven discrete configurations were devised to drive the project. The intervention period has allowed comparison of the academic years 2017/18 to 2018/19.

For IMG demographics and COP related information see Table 2. Mean age of the IMG cohort was $31 \pm 3$ years and $52 \%$ were female. The participant cohort is described in Fig 2. Of the 31 IMGs recruited, 23 doctors were included in the subsequent analysis. The COP (Fig 1) was completed in $96 \%$. Overall mean employment contract duration stood at $13 \pm 5$ months. Objective clinical achievements during the period of employment for the whole cohort of IMGs included successful completion of external accredited courses such as Advanced Life Support $(n=17)$ and Ill Medical Patients' Acute Care \& Treatment $(n=10)$. IMGs also passed formal clinical examinations including Membership of the Royal College of Physicians (UK) part $1(n=2)$, part 2 written $(n=2)$ and Practical Assessment of Clinical Examination Skills $(n=3)$ while as trust employees. Three recruits have entered UK-based training posts (internal medicine training $(n=1)$; general practice vocational training scheme $(n=1)$; and higher specialist training in respiratory medicine $(n=1)$ ). Two participants have been locally appointed from $\mathrm{SHO}$-grade to trust registrar-grade positions through open competition. Furthermore, three doctors presented or will present their local training experience at national conferences. To date, $83 \%$ of eligible IMGs have successfully completed their formal annual appraisal.

Over the intervention period from academic year 2017/2018 to $2018 / 19$, the mean JD post occupancy has risen from $54 \pm 3$ JDs to $73 \pm 4 \mathrm{JDs}(p<0.001)$. There has been a $£ 1.9$ million reduction in agency and locum JD spend in the division. Exception reporting by trainee JDs has fallen by $56 \%$. Formal complaints from patients and their families have fallen by $11 \%$. Length of stay has reduced from $9.3 \pm 16.4$ days to $8.9 \pm 15.6$ days $(p=0.035)$ over the same intervention study period. For the first time since its inception, the Care Quality Commission (CQC) has rated our organisation including the medicine division as 'Good' (from 'Requires Improvement') during the academic year 2018/2019.

\section{Discussion}

To our knowledge, this is the first study describing the design and implementation process of a recruitment and structured COP for IMGs naive to the NHS. We outline a recruited IMG cohort, their demographic data and COP-related milestones, 
Table 1. Context-mechanism-outcome configurations

\section{Contexts}

Shortage of JDs resulting in increased recruitment of temporary staff at premium rates and inconsistent clinical care

Poor performance and low level of wellbeing in the initial stages at the workplace among new entrant IMGs

Risks to patient safety due to poor knowledge of contextual factors including policies and procedures by the new entrant IMGs

Managers' uncertainty about recruitment and orientation of new entrant IMGs

Lack of standardised communication channels between JDs, their supervisors and the trust management

Availability of on-site staff accommodation in the trust

Lack of criteria for assessment and unrealistic expectations from new entrant IMGs during their orientation

\section{Mechanisms}

Employing new entrant IMGs at standard NHS salary

Structured intervention during the orientation period including a good learning environment, adequate mentoring and pastoral support will help to overcome these problems

Providing clear communication of curriculum competencies along with peer support to

these doctors

Holding meetings with managers to discuss the design and implementation of the intervention

Developing a standardised communication strategy will facilitate effective communication of critical success factors

Providing free accommodation to doctors doing honorary clinical attachment

Tailoring the intervention based on requirements of JDs, their supervisors and managers of the trust

\section{Outcomes}

A stable workforce leading to improved clinical care and financial position of the trust

Improvement in the participation, selfefficacy and learning of these doctors

Improvement in the awareness among these doctors of the contextual factors contributing to the provision of highquality patient care

Increased participation and support of managers for the intervention

The stakeholders perceive that their voice is being heard and they are valued resulting in their increased satisfaction

Improved cost efficiency of the trust by attracting overseas JDs into honorary posts, increasing their recruitment

Clarity of roles and requirements and better participation of the stakeholders

$\mathrm{IMG}=$ international medical graduate; $J \mathrm{D}=$ junior doctor

and clinically salient achievements through their period of employment. Furthermore, we describe the impact of these interventions on indicators of JD wellbeing and workforce stability, patient care and financial sustainability. Finally, we present the

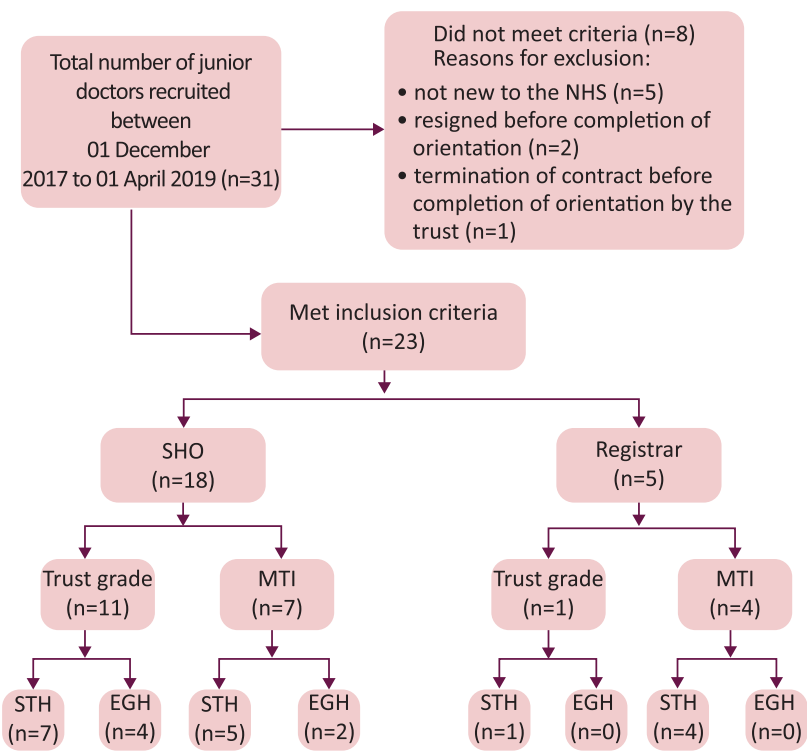

Fig 2. Participant cohort of recruited international medical graduate junior doctors. $\mathrm{EGH}=$ Epsom General Hospital; MTI = Medical Training Initiative; $\mathrm{SHO}=$ senior house officer; $\mathrm{STH}=$ St Helier and Queen Mary's Hospital for Children. quality improvement process and anticipated outcomes of the intervention using the realist evaluation approach in the form of seven $\mathrm{CMO}$ configurations.

This study has involved recruitment of one of the largest described cohorts of new entrant IMGs into a GIM department by any NHS trust in the UK. Moreover, we have shown excellent retention of these doctors. For quality assurance and patient safety motives, there has been a particular focus on a structured COP for registrar-grade IMGs new to the NHS. Due to the complexity of the duties of the on-call medical registrar, particularly during out-of-hours work, ensuring adequate training to an appropriate level during the orientation period was a fundamental aim. By adapting the COP, where requested by individuals, we have applied the same principles of assessment to also up-skill interested UK trainees, supporting the transition from $\mathrm{SHO}$ to registrar-grade on-call activities to aid career development in a supported environment. The integration of UK trainees and IMGs has been mutually beneficial and so the rewards of a stable and fully staffed junior doctor team.

Unfortunately, there is no UK-based literature to benchmark our structured COP. Internationally, a compulsory 3-month structured assessment is described in Canada for new entrant IMGs into residency programmes. ${ }^{25}$ Upon successful completion, full access to the residency programme is provided. ${ }^{25}$ Similarly, structured induction and orientation criteria for all new entrant IMGs have been developed by the Medical Council of New Zealand. ${ }^{26}$

Of the new IMGs recruited to our trust, $96 \%$ successfully completed the COP and many have made significant professional achievements during their employment. Though individual achievements may not be directly related to the interventions we 
Table 2. Demographic data and programme-related information of junior doctors

\begin{tabular}{|c|c|c|c|}
\hline Category & All doctors & SHO grade & Registrar grade \\
\hline Number, $\mathrm{n}$ & 23 & 18 & 5 \\
\hline Age, years, mean $\pm S D$ & $31 \pm 3$ & $31 \pm 3$ & $33 \pm 4$ \\
\hline Female, \% & 52 & 61 & 20 \\
\hline Ethnicity (Asian/White/Black African), \% & $78 / 13 / 9$ & $72 / 17 / 11$ & $100 / 0 / 0$ \\
\hline Religion (Islam/Hinduism/Christianity/Buddhism), \% & $43 / 35 / 18 / 4$ & $50 / 28 / 17 / 5$ & $20 / 60 / 20 / 0$ \\
\hline Marital status (single/married), \% & $56 / 44$ & $66 / 34$ & $20 / 80$ \\
\hline Profession of spouse (doctor or dentist/other), \% & $70 / 30$ & $50 / 50$ & $100 / 0$ \\
\hline Country of PMQ (India/Bangladesh/other), \% & $48 / 17 / 35$ & $39 / 22 / 39$ & $80 / 0 / 20$ \\
\hline $\begin{array}{l}\text { Duration between time completing PMQ and starting first job in the } \\
N H S \text {, years, mean } \pm S D\end{array}$ & $7 \pm 3$ & $6 \pm 3$ & $8 \pm 3$ \\
\hline $\begin{array}{l}\text { Highest professional qualification (MBBS/MD/MRCP(I)/MRCP1 or } \\
\text { MRCP2), \% }\end{array}$ & $35 / 17 / 8 / 40$ & $45 / 5 / 0 / 50$ & $0 / 60 / 40 / 0$ \\
\hline Root to GMC registration (PLAB/MTI), \% & $48 / 52$ & $56 / 44$ & $20 / 80$ \\
\hline Visa status (Tier 2/Tier 5/dependent/British citizen), \% & $40 / 44 / 12 / 4$ & $45 / 39 / 11 / 5$ & $20 / 60 / 20 / 0$ \\
\hline Have attended honorary clinical attachment, \% & 35 & 45 & 0 \\
\hline Successfully completed orientation programme, \% & 96 & 94 & 100 \\
\hline Currently working in the trust, \% & 87 & 83 & 80 \\
\hline Duration of time worked in the trust, months, mean $\pm S D$ & $13 \pm 5$ & $13 \pm 5$ & $13 \pm 6$ \\
\hline
\end{tabular}

GMC = General Medical Council; MBBS = Bachelor of Medicine and Bachelor of Surgery; MD = Doctor of Medicine; MRCP(I) = Member of Royal College of Physicians of Ireland; MTI = Medical Training Initiative; PLAB = Professional and Linguistic Assessment Board; PMQ = primary medical qualification; SD = standard deviation; $\mathrm{SHO}=$ senior house officer.

describe, we do believe they are facilitated and attributed at least in part to their clinical exposure, learning opportunities and clinical support during the course of their working contract and align similarly with opportunities for our UK-based trainee doctors. Since the majority of the IMGs remain employed with the trust, they will continue to receive support and encouragement to achieve further learning goals.

It is also important to note that over the early months of this project we have seen the significant clinical progress of newly recruited IMGs. We anticipate further academic progress as individuals settle into their respective job roles. Therefore, their overall academic potential (and indirect benefit to the NHS) may be significantly underestimated during this early period.

In summary, the intervention has demonstrated clinical benefit in the form of reduced length of stay, complaints and trainee JD exception reporting as well as a reliance on expensive locum and agency JDs. Also, the significant impact on financial sustainability has allowed for an expansion in JD numbers on fixed-term NHS contracts. Finally, the intervention has also coincided with a transformation in the CQC ratings not only for the division but also for our trust over the study period from 'Requires Improvement' to 'Good'. Our workforce intervention methodology and COP is readily transferrable and could be applied more widely to other clinical settings in the NHS.

\section{Limitations of the study}

As often with change management and implementation, our project has required significant time and resources to engage key stakeholders in developing processes impacting on a wide range of departments and services. Evolution has been iterative. It has been important to develop system processes that have allowed for a more sustainable solution that is less dependent on individuals.

The project was born from a service need to support the recruitment of a reliable and sustainable addition to the GIM workforce. While much of the methodology can be applied to other clinical settings, the emergency department for example, this was not part of the original brief and transferability of the interventions would need to be adapted and possibly expanded. To ensure a robust process of developing and expanding the CMO configurations, while minimising the level of subjective interpretation, a dedicated and limited team of researchers is, however, recommended. Nevertheless, the formal structure of the project does provide a powerful framework to apply similar strategies more broadly to face a rising challenge to manage the UK healthcare workforce.

\section{Conclusions}

In this study, we have developed innovative strategies to improve recruitment and retention of JDs to our trust. We have particularly focused on a structured COP for new IMGs naive to the NHS resulting in their smooth, safe and supported transition into the workplace. We have demonstrated significant clinical and financial benefits from our intervention and recommend its widespread use.

\section{Acknowledgements}

We thank Mr Michael Dennis, HR junior doctors' recruitment project lead, Epsom \& St Helier University Hospitals NHS Trust, for assistance with clarification and streamlining of the recruitment process and Ms 
Kemi Alade, HR recruitment manager, Epsom \& St Helier University Hospitals NHS Trust, for fully supporting a the recruitment drive for junior doctors. We would also like to show our gratitude to Ms Anjali Goel, recruitment advisor, Epsom \& St Helier University Hospitals NHS Trust, for her assistance and dedication in implementing a responsive recruitment programme. We are also immensely grateful to Karen Williams, deputy general manager of the medicine division, Epsom \& St Helier University Hospitals NHS Trust, for her assistance with the junior doctor staff allocation in the various medical wards.

\section{References}

1 Age UK. Later life in the United Kingdom 2019. Age UK, 2019. www.ageuk.org.uk/globalassets/age-uk/documents/reports-andpublications/later_life_uk_factsheet.pdf [Accessed 17 May 2019].

2 Stoye G. What do we know about the effects of cutting public funding for social care? The Health Foundation, 2018. www.health. org.uk/blogs/what-do-we-know-about-the-effects-of-cutting-publicfunding-for-social-care [Accessed 12 May 2019]

3 The Health Foundation. Health and social care funding explained. The Health Foundation, 2017. www.health.org.uk/chart/healthand-social-care-funding-explained [Accessed 25 May 2019].

4 Moberly T. Number of women entering medical school rises after decade of decline. BMJ 2018;360:k254.

5 Thomas JM. Why having so many women doctors is hurting the NHS: A provocative but powerful argument from a leading surgeon. Mail Online, 2014. www.dailymail.co.uk/debate/ article-2532461/Why-having-women-doctors-hurting-NHS-Aprovovcative-powerful-argument-leading-surgeon.html [Accessed 13 May 2019].

6 General Medical Council. The state of medical education and practice in the UK. GMC, 2018. www.gmc-uk.org/somep2018 [Accessed 8 May 2019].

7 Royal College of Physicians. Brexit: What does it mean for doctors? London: RCP, 2020. www.rcplondon.ac.uk/projects/outputs/brexitwhat-does-it-mean-doctors [Accessed 11 March 2020].

8 NHS Employers. Junior doctors' terms and conditions of service March 2017. NHS Employers, 2017. www.nhsemployers.org/ case-studies-and-resources/2017/03/junior-doctors-terms-andconditions-of-service-march-2017 [Accessed 20 June 2019].

9 Addelman M. Uncertainty surrounding junior doctors' contract affected career choice, study reveals. The University of Manchester, 2017. www.manchester.ac.uk/discover/news/uncertaintysurrounding-junior-doctor-contracts-affected-career-choice-studyreveals [Accessed 8 May 2019].

10 Rimmer A. Number of British doctors working in Australia and New Zealand is rising. BMJ 2017;359:j4554.

11 General Medical Council. What our data tells us about locum doctors. GMC, 2018. www.gmc-uk.org/-/media/documents/what-ourdata-tells-us-about-locum-doctors_pdf-74371150.pdf [Accessed 28 May 2019].

12 NHS Employers. Working time directive. NHS Employers, 2009. www.nhsemployers.org/ /media/Employers/Documents/
SiteCollectionDocuments/WTD_FAQs_010609.pdf [Accessed 22 May 2019].

13 Wilson HCP, Simpkin AL. Why are so many doctors quitting the NHS? It's time to ask the right questions. BMJ, 2019. https://blogs bmj.com/bmj/2019/01/25/why-are-so-many-doctors-quitting-thenhs-its-time-to-ask-the-right-questions/

14 Al-Attar M. 5 new medical schools to open in England. The Medic Portal, 2019. www.themedicportal.com/blog/five-new-medicalschools-open-england [Accessed 16 May 2019].

15 British Medical Association. The contribution of international medical graduate doctors to the NHS. BMA, 2015. www.bma.org. uk/-/media/files/pdfs/about the bma/equality and inclusion/the contribution of imgs to the nhs-pdf.pdf [Accessed 20 May 2019].

16 Hughes D, Clarke V. Thousands of NHS nursing and doctor posts lie vacant. BBC News, 2016. www.bbc.co.uk/news/health-35667939 [Accessed 21 June 2019].

17 Moberly T. Number of locums has doubled since 2009. BM] 2016;355:i6206

18 NHS. Interim NHS people plan. NHS, 2020. www.longtermplan. nhs.uk/wp-content/uploads/2019/05/Interim-NHS-People-Plan_ June2019.pdf [Accessed 11 March 2020].

19 Bhat M, Ajaz A, Zaman N. Difficulties for international medical graduates working in the NHS. BMJ 2014;348:g3120.

20 Bourne $S$. What are the biggest challenges international medical graduates face when starting work in the NHS? BMJ 2018;360:j5618.

21 Slowther A, Lewando Hundt G, Purkis ], Taylor R. Experiences of non-UK-qualified doctors working within the UK regulatory framework: a qualitative study. J R Soc Med 2012;105:157-65.

22 Hashim A. Educational challenges faced by international medical graduates in the UK. Adv Med Educ Pract 2017;8:441-5.

23 Pawson R, Tilley N. Realistic evaluation, 1st edn. London: Sage Publications, 1997.

24 Nielsen K, Miraglia M. What works for whom in which circumstances? On the need to move beyond the 'what works?' question in organizational intervention research. Human Relations 2016;70:40-62.

25 University of Toronto. Assessment Verification Period (AVP): For IMGs entering PGME in Ontario. University of Toronto, 2019. https://pg.postmd.utoronto.ca/about-pgme/policies-guidelines/ assessment-verification-period-avp [Accessed 25 May 2019].

26 Medical Council of New Zealand. Orientation induction and supervision for international medical graduates. Medical Council of New Zealand, 2011. https://www.mcnz.org.nz/assets/Publications/ Booklets/11ab55b654/Orientation-Induction-and-Supervision-forInternational-Medical-Graduates.pdf.

Address for correspondence: Dr Syed Rehan Quadery, Department of Respiratory Medicine, St Helier Hospital, Epsom and St Helier University Hospitals NHS Trust, Carshalton SM5 1AA, UK.

Email: rehan.quadery@nhs.net 